NBER WORKING PAPER SERIES

\title{
THE CYCLICAL RESPONSE OF ADVERTISING REFUTES COUNTER-CYCLICAL PROFIT MARGINS IN FAVOR OF PRODUCT-MARKET FRICTIONS
}

\author{
Robert E. Hall \\ Working Paper 18370 \\ http://www.nber.org/papers/w18370 \\ NATIONAL BUREAU OF ECONOMIC RESEARCH \\ 1050 Massachusetts Avenue \\ Cambridge, MA 02138 \\ September 2012
}

The Hoover Institution supported this research. The research is also part of the National Bureau of Economic Research's Economic Fluctuations and Growth Program. I am grateful to Kyle Bagwell, Mark Bils, Valerie Ramey, Julio Rotemberg, Stephen Sun, and Michael Woodford for valuable comments. The views expressed herein are those of the author and do not necessarily reflect the views of the National Bureau of Economic Research.

NBER working papers are circulated for discussion and comment purposes. They have not been peerreviewed or been subject to the review by the NBER Board of Directors that accompanies official NBER publications.

(C) 2012 by Robert E. Hall. All rights reserved. Short sections of text, not to exceed two paragraphs, may be quoted without explicit permission provided that full credit, including $\bigcirc$ notice, is given to the source. 
The Cyclical Response of Advertising Refutes Counter-Cyclical Profit Margins in Favor of Product-Market Frictions

Robert E. Hall

NBER Working Paper No. 18370

September 2012

JEL No. D43,E12,E32

\begin{abstract}
According to the standard model, advertising is remarkably sensitive to profit margins. Firms advertise to stimulate demand for their products. They advertise high-margin products aggressively and low-margin ones hardly at all. In macroeconomics, variations in profit margins over the business cycle have a key role. A widening of margins can explain the rise in unemployment in recessions. A higher margin implies a lower real wage. A variety of models ranging from Keynesian to search-and-matching map a decline in wages to higher unemployment. But a rise in profit margins should expand advertising by a lot. Really a lot. Advertising should be highly countercyclical. Instead, it is somewhat procyclical. The ratio of advertising spending to private GDP falls when the economy contracts. The behavior of advertising refutes the hypothesis that profit margins rise. But it is true that the labor share of income falls. Hence there must be another factor that lowers the labor share without raising profit margins. The only influence that fits the facts is a rise in a product-market friction that has the same effect as an increase in sales taxes.
\end{abstract}

Robert E. Hall

Hoover Institution

Stanford University

Stanford, CA 94305-6010

and NBER

rehall@gmail.com 
Theorem: Let $R$ be the ratio of advertising expenditure to the value of output. Let $-\epsilon$ be the residual elasticity of demand. Let $m$ be an exogenous shift in the profit margin. Then the elasticity of $R$ with respect to $m$ is $\epsilon-1$, which is a really big number.

After proving this theorem, which is a direct implication of the standard model of advertising, I dwell on its implications for an important issue in macroeconomics, the role of shifts in the profit margin. The basic idea is simple. In a slump, firms do not cut prices in answer to disappointing sales. If their costs are lower-because they have moved down their upward-sloping short-run marginal costs curves or because flexible-price factor markets now have lower prices - their profit margins are higher. The theorem says that they should expand advertising by substantial amounts. Consider the middle-of-the-road value for the typical residual elasticity of demand of 6 , so that the ratio of price over marginal cost is $6 /(6-$ $1)=1.2$ The ratio of advertising spending to GDP should rise by 5 times the proportional increase in that ratio. Advertising should be highly countercyclical. Firms should expand advertising aggressively in a slump.

In fact, advertising is procyclical. I show that the ratio of advertising to GDP falls by about one percent for each percentage point of extra unemployment. Far from boosting advertising to recover business lost in a slump, firms cut advertising by even more than their loss of sales. The key finding, however, is that advertising is not highly countercyclical. I would have written this paper even if I had found advertising to be noncyclical or mildly countercyclical.

The thrust of standard advertising theory is that advertising should rise and fall in proportion to sales. The formula for the ratio is remarkably simple; it is the elasticity of sales with respect to advertising effort divided by the residual elasticity of demand. If the two elasticities are constants not influenced by the factors causing a slump, then advertising will be a constant fraction of sales. Macroeconomics has brought into play a mechanism not usually considered in advertising theory, namely that profit margins widen in slumps. That widening should result in a splurge of advertising in slumps.

The question at this point is what other factor could be operating to alter the standard property that implies that advertising should be neither procyclical (as it actually is) nor countercyclical (as the widening-margin model implies). In my baseline model, I include a friction that has the effect on a firm that a sales tax would. I call this a product-market fric- 
tion. I use the term wedge to describe the shift in the profit margin and the product-market friction. This term is widely used in macroeconomics to describe variables that measure gaps between theoretical first-order conditions and the actual values of the corresponding variables.

The paper studies two key observed variables: (1) the ratio of advertising spending to revenue, and (2) the ratio of labor compensation to revenue (the labor share). Both the profitmargin wedge and the product-market friction wedge affect these variables. The elasticity of the advertising ratio with respect to the profit-margin wedge is $\epsilon-1$, a number around 5 . The elasticities of the advertising ratio with respect to the product-market friction wedge and of the labor share with respect to both wedges are all -1 . The fact that the profit-margin wedge has a large effect on the advertising ratio has a neat implication. Consider the ratio of the advertising/sales variable to the labor share. One fact is that the elasticity of that ratio with respect to the product-market friction is zero, because the friction has the same effect on numerator and denominator. The second fact is that the elasticity of the ratio with respect to the profit-margin wedge is the residual elasticity of demand, $\epsilon$, say 6 . These facts provide a clean identification of the role of the profit-margin wedge. That wedge should have a big positive effect on advertising in recessions, under the view that profit margins increase in recessions. A regression of the ratio of the advertising/sales variable to the labor share on employment should have a big negative coefficient that arises entirely from the margin effect and not at all from the product-market friction. In reality, the regression coefficient is slightly positive and the confidence interval around it excludes any big negative effect. The finding casts serious doubt on the countercyclical profit-margin hypothesis

On the other hand, the product-market friction emerges as a fully consistent idea about the character of slumps. It says that rising frictions in recessions lower advertising and the labor share about equally, leaving the ratio of the two variables close to noncyclical. I avoid speculation in this paper about the nature of the friction.

I consider a number of potential variations around the basic specification in the paper. The first is to follow an important branch of the advertising literature and treat advertising expenditure as a form of investment. Because investment in, say, plant and equipment is quite procyclical, this consideration might explain the findings despite a countercyclical marginthe procyclical effect from investment might be swamping the large countercyclical effect of the margin changes. But a reformulation of the model using standard investment theory 
shows otherwise. A key factor in this finding is the high depreciation rate of advertising. A consensus of research on advertising is that around 60 percent of the effect of earlier advertising dissipates each year.

I also consider a model extended to include other cyclical shifts. These are (1) changes in productivity, (2) measurement error in the labor share, (3) measurement error in the capital share, and (4) measurement error in the price of advertising. I show that productivity and capital measurement errors have no effect on the measured values of the variables I study. Of course, they do affect other variables - the point is that they drop out of the ratios I consider. A plausible measurement error in the labor share - an idea I take seriously - goes in the wrong direction to overcome the findings. Measurement error in the price of advertising could conceal part of its countercyclical movements but would have to be implausibly large to overturn the basic conclusion of the paper. The most likely form of such an error would come from failing to consider the investment component of advertising, a topic I consider separately with negative conclusions.

\section{Related Research}

\subsection{Cyclical behavior of advertising}

Borden (1942) noted the close correlation between advertising volume and an index of industrial production - see Simon (1970), Figures 2-11 and 2-12, who also cites a number of other sources confirming the correlation. Kaldor (1950) noted a similar correlation and Blank (1962) and Yang (1964) documented the correlation, without theoretical interpretation. Bils (1989), Table 1, presents regressions of the rate of change of real advertising expenditures on the rate of change of real GDP. A coefficient greater than one would indicate procyclical movements as that term is used in this paper. He uses data for the U.S. and Britain. In all cases the coefficients are positive and for more recent U.S. data and all British data, they exceed one. The model in the paper implies countercyclical market power for reasons similar to Edmond and Veldkamp (2009), discussed below, but Bils interprets the model as pointing toward procyclical advertising.

\subsection{The level of market power}

Positive advertising expenditure proves the existence of market power, for there is no incentive to advertise in perfectly competitive markets. Still, there is remarkably little consensus 
on the extent of market power in the U.S. economy. The most recent survey of the subject appears to be Bresnahan (1989). His summary, in Table 17.1, reports residual elasticities in the range from 1.14 to 40, for industries from coffee roasting to banking. Many subsequent studies, mainly for consumer packaged goods, have appeared since the publication of Bresnahan's survey. I am not aware of any attempt to distill a national average from studies for individual products. Hausman, Leonard and Zona (1994), for example, study the demand for beer and find residual elasticities (holding the prices of competing beers constant) in the range from 3.5 to 5.9. Most research does not try to reconcile residual elasticities estimated from demand equations with data on price/marginal cost ratios from producers, though Bresnahan discusses this topic extensively. De Loecker and Warzynski (2012) use firm-level from Slovenia in a producer-side framework and find average markups of about 1.2 , corresponding to a residual elasticity of demand of 6 , the value I take in my base case.

\subsection{Cyclical changes in market power}

Macroeconomics has spawned a large literature on countercyclical market power. Bils (1987) launched the modern literature that studies cyclical variation in the labor share. My interpretation of that literature is that it measures not variations in profit margins but rather in the labor share, because these are not the same thing in the presence of the product-market friction that I consider. Bils made important adjustments based on cyclical variations in the incidence of overtime wages. Rotemberg and Woodford (1999) embraced Bils's adjustments in a survey chapter that explains how New Keynesian models explain cyclical variations in output and employment through variations in market power resulting from sticky prices and flexible cost. Nekarda and Ramey (2010) and Nekarda and Ramey (2011) challenge the findings of countercyclical market power in favor of cyclically constant markups resulting from Bils's overstatement of the incidence and magnitude of overtime premiums.

Bils and Kahn (2000) argue that marginal cost is procyclical because firms internalize the fluctuations in their employees' disamenity of work effort. In slumps, the marginal disamenity of effort is low, because effort itself is low. In an expansion, as effort rises, its marginal burden on workers rises and marginal cost of production rises accordingly, even if cash payments to workers do not rise in proportion to the marginal burden. They use this hypothesis to explain the otherwise puzzling behavior of inventory investment. Firms allow inventory levels to decline persistently below normal during booms and above normal 
in slumps, which would only make sense if marginal production costs are high in booms and low in slumps.

Chevalier and Scharfstein (1996) develop and estimate a model in which capital-market frictions influence pricing decisions at the retail level. In slumps, firms that are financially constrained disinvest in customers by setting prices at higher than normal margins over marginal cost.

Edmond and Veldkamp (2009) look at the issues of market power from the consumer's perspective. They find that rising dispersion of income distribution lowers residual elasticities in slumps. Firms respond by setting prices further above marginal cost.

The literature on cyclical changes in market power is complementary to the ideas in this paper. In many of the accounts in the existing literature, the question becomes acute: Why does advertising not expand in slumps when the residual elasticity falls?

\subsection{Cyclical fluctuations in product-market friction}

I am not aware of any work on this topic.

\section{Theory}

Suppose that the residual demand facing a firm is a constant-elastic function of the firm's price $p$, the average $\bar{p}$ of its rivals' prices, its own advertising $A$, and the average of its rivals' advertising $\bar{A}$, with elasticities $-\epsilon, \bar{\epsilon}, \alpha$, and $-\bar{\alpha}$. The marginal cost of production is $c$ and the cost of a unit of advertising is $\kappa$. Although customers pay $p$ for each unit of output, the firm receives only $p / f$, where $f$ is a product-market friction or wedge that depresses the price the firm receives. The factor $f$ may be above or below 1 . The firm's objective is

$$
\max _{p, A}\left(\frac{p}{f}-c\right) p^{-\epsilon} \bar{p}^{\bar{\epsilon}} A^{\alpha} \bar{A}^{-\bar{\alpha}}-\kappa A
$$

The profit-maximizing price is

$$
p^{*}=\frac{\epsilon}{\epsilon-1} f c
$$

and in symmetric equilibrium, $\bar{p}=p$ and $\bar{A}=A$. For some reason-possibly price stickinessthe firm actually sets the price

$$
p=m p^{*}
$$


The profit-margin wedge, $m$, may be above or below 1 . If $m>1$, the firm keeps the added profit per unit sold though it loses profit overall from the reduced volume. The reverse occurs if $m<1$.

Equation (2) and equation (13) imply

$$
p=m f \frac{\epsilon}{\epsilon-1} c .
$$

The variable part of the markup of price $p$ over marginal cost $c$ is the product of the two wedges, $m f$. The profit-margin wedge has implications stressed in Rotemberg and Woodford (1999) and is the way that sticky prices affect real allocations, as those authors explain. On the other hand, the friction $f$ also appears in equation (1), where it has the effect of taking away the margin increase from the firm, so an increase in $f$ does not raise profit. Consequently, the two wedges have quite different effects. Later in the paper I will demonstrate that authors thinking they are measuring the profit-margin wedge $m$ by studying labor's share of total cost are actually measuring the compound wedge $m f$, under the assumptions of this model.

\subsection{Advertising}

The first-order condition for advertising is

$$
\frac{\alpha}{A} Q\left(\frac{p}{f}-c\right)=\kappa
$$

Rearranging and dividing both sides by $p$ yields an expression for the ratio of advertising expenditure to revenue:

$$
\frac{\kappa A}{p Q}=\alpha \frac{p / f-c}{p}
$$

Substituting for $p$ from equation (13) and for $p^{*}$ from equation (2) restates the right-hand side in terms of exogenous influences:

$$
R=\frac{\kappa A}{p Q}=\alpha \frac{(m-1) \epsilon+1}{f m \epsilon}
$$

Absent the special influences captured by $f$ and $m$, that is, with $f=m=1$, the advertising/revenue ratio is

$$
R=\frac{\alpha}{\epsilon},
$$

a standard result in the advertising literature, first derived by Dorfman and Steiner (1954). See Bagwell (2007) for an impressively complete review of the literature on the economics of advertising. 
From these equations, two useful results follow:

Proposition Rm: The elasticity of the advertising ratio $R$ with respect to the profit-margin shockwedge $m$ at the point $f=m=1$ is $\epsilon-1$.

Proposition Rf: The elasticity of the advertising ratio with respect to the friction $f$ is -1 .

Proposition $\mathrm{Rm}$ is the centerpiece of the paper-advertising is highly sensitive to the profit-margin wedge. If markups rise in a slump, firms should increase efforts aggressively to attract new customers and retain existing ones, because selling to them has become more profitable.

\subsection{Labor share}

The second measure is the labor share

$$
\lambda=\frac{W}{p Q}
$$

Here $W$ is the firm's total wage bill including all forms of compensation. Under the assumptions of Cobb-Douglas technology with labor elasticity $\gamma$ and cost minimization, the wage bill is $\gamma c Q$, so

$$
\lambda=\frac{\gamma c Q}{p Q}=\gamma \frac{\epsilon-1}{\epsilon} \frac{1}{f m}
$$

Two additional results then follow immediately:

Proposition $\lambda \mathbf{m}$ : The elasticity of the labor share $\lambda$ with respect to the profit-margin wedge $m$ is -1 .

Proposition $\lambda \mathbf{f}$ : The elasticity of the labor share with respect to the product-market wedge $f$ is -1 .

\subsection{Solving for the wedges}

From the propositions above,

$$
\log R=(\epsilon-1) \log m-\log f+\mu_{R}
$$

and

$$
\log \lambda=-\log m-\log f+\mu_{\lambda}
$$

where $\mu^{R}$ and $\mu^{\lambda}$ are constant and slow-moving influences apart from $m$ and $f$. 
Solving this pair of equations for $\log m$ and $\log f$ yields

$$
\log m=\frac{\log R-\log \lambda}{\epsilon}+\mu_{m}
$$

and

$$
\log f=-\log \lambda-\frac{\log R-\log \lambda}{\epsilon}+\mu_{f}
$$

Here $\mu_{m}$ and $\mu_{f}$ are constant and slow-moving influences derived in the obvious way from $\mu_{R}$ and $\mu_{\lambda}$.

\subsection{The role of cyclical movements}

The main goal of this paper is to study movements of the observed time series $R$ and $\lambda$ and make inferences about the cyclical movements of the inferred wedges $m$ and $f$, especially to quantify their contributions to the business cycle. Throughout the paper, I measure the business cycle by the employment rate, the fraction of the labor force holding jobs (one minus the unemployment rate). Variables are procyclical if they move positively with the employment rate and countercyclical if they move negatively. The data show that the advertising/sales ratio $R$ and the labor share $\lambda$ are quite procyclical. The expectation is that the wedges are both countercyclical-they measure forces that cause reductions in employment when they rise.

\section{Cyclical Movements of Advertising/GDP Ratio and the Labor Share}

For many years, Robert J. Coen of the ad agency Erickson-McCann published a compilation of data on advertising expenditure. I was unable to find any surviving original copy of his data. Douglas Galbi posted a copy of Coen's estimates through 2007 in his blog, along with estimates for early years from other sources. Galbi also provides links to Coen's data sources, but the only one still active is for the data on newspapers. Further information about the sources appears in the appendix.

For 2005 through 2010, the Census Bureau has published revenue data for NAICS industry 51, the information sector, which includes the advertising industries. I define advertising as the sum of newspapers, magazines, broadcasting, and Internet. In the three years that the Census figures overlap Coen's, the latter is 1.38 times the former. I take the figures for 2008 through 2010 to be this factor times the Census figure. 
I am continuing to explore alternative data sources for advertising spending, at the aggregate and industry levels. The Internal Revenue Service publishes data for corporate advertising deductions for recent years and possibly for earlier years, but only on paper.

Figure 1 shows the ratio of advertising spending to private nominal GDP, stated as an index, with vertical bars shaded darker in years when the employment rate was low.

The data run from 1950 through 2010. In addition to total advertising, I also estimate equations for the major components: TV, radio, newspapers, direct mail, and other. Table 1 shows the results. In all cases but one, the estimated cyclical response - the coefficient on the employment rate-is positive, generally statistically unambiguously positive. The relationship is much stronger for the AR specification of the low-frequency component- the HP and bandpass filters plainly absorb a good deal of the variation in the advertising/GDP ratio that would otherwise be associated with employment.

I form

$$
R=\frac{\kappa A}{p Q}
$$

as the ratio of advertising expenditure to private nominal GDP. Recall that the model for this variable is

$$
\log R=(\epsilon-1) \log m-\log f+\mu_{R} .
$$

To characterize the cyclical behavior of $R$, I use the regression

$$
\log R_{t}=\beta_{R} L_{t}+\mu_{R, t}
$$

Here the coefficient $\beta_{R}$ multiplying the employment rate $L_{t}$ measures the procyclicality of $R$. $\mu_{R, t}$ is a residual with substantial low-frequency movements unrelated to the business cycle. I model the low-frequency variation $\mu_{R}$ in a number of ways. The first is as a random walk:

$$
\mu_{R, t}=\omega_{R}+\frac{1}{1-\mathbb{L}} \eta_{t}
$$

where $\omega_{R}$ is a constant, $\mathbb{L}$ is the lag operator, and $\eta_{R, t}$ is a white-noise innovation. The second is as a deterministic linear trend plus a highly serially correlated random component:

$$
\mu_{R}=\omega_{R}+\tau_{R} t+\frac{1}{1-\rho \mathbb{L}} \eta_{t}
$$

where $\tau_{R}$ is the linear trend. I omit the second specification if the estimated $\rho$ exceeds one.

The third and fourth models take the slow-moving component to be a filtered version of $R_{t}$, say $\bar{R}_{t}$, and estimate

$$
\log \left(R_{t} / \bar{R}_{t}\right)=\omega_{R}+\beta_{R} L_{t}+\eta_{R, t}
$$




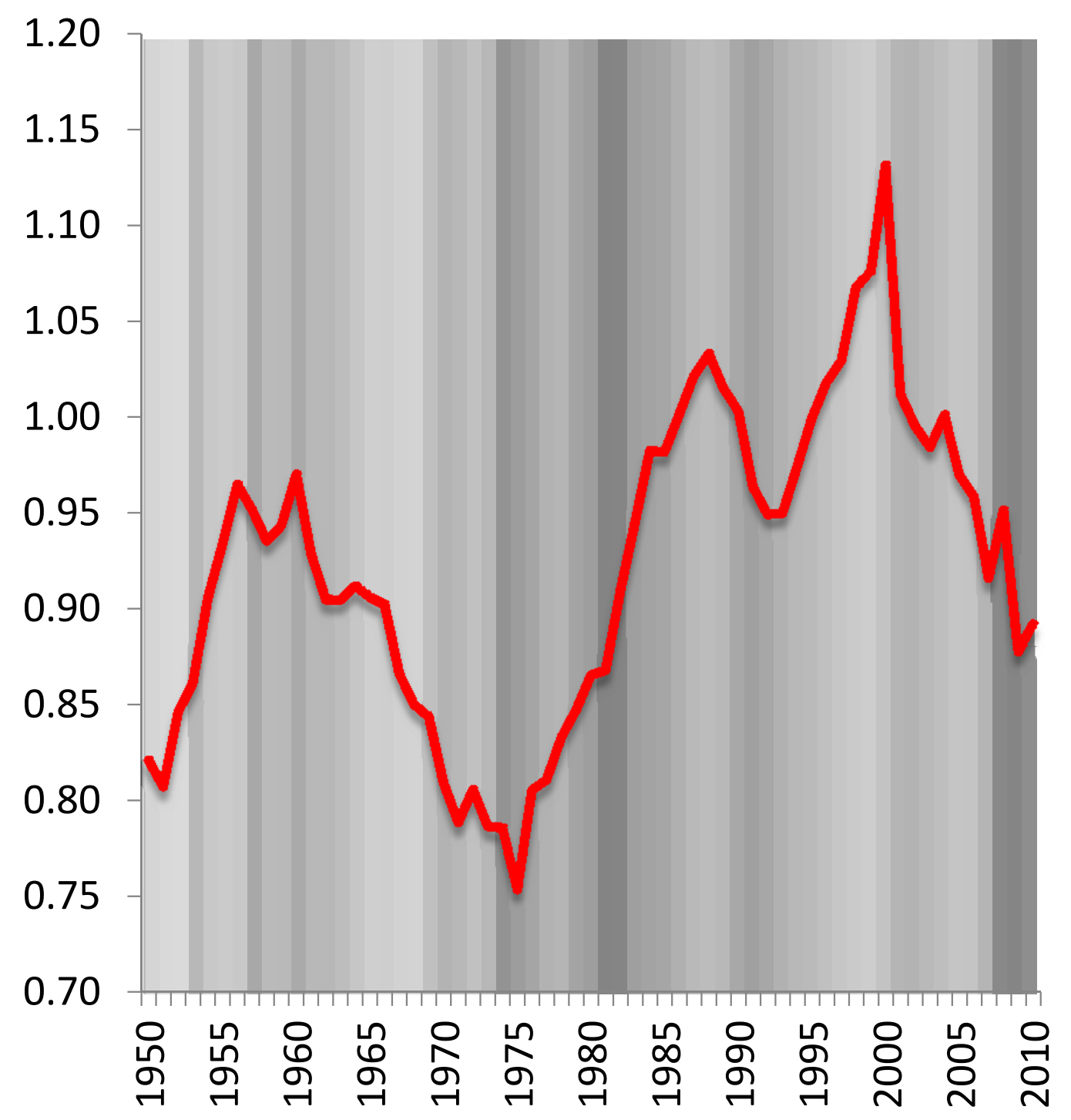

Figure 1: Index of the Ratio of Advertising Spending to Private GDP, with Shading in Proportion to the Employment Rate 


\begin{tabular}{|c|c|c|c|c|c|c|}
\hline \multirow{2}{*}{ Left-hand variable } & \multicolumn{6}{|c|}{ Coefficients and standard errors } \\
\hline & \multicolumn{2}{|c|}{ Employment rate } & \multicolumn{2}{|c|}{ Trend } & \multicolumn{2}{|c|}{ Autoregressive term } \\
\hline $\begin{array}{l}\text { types of } \\
\text { advertising/GDP }\end{array}$ & 0.97 & $(0.37)$ & - & - & - & - \\
\hline $\begin{array}{l}\text { Log of all types of } \\
\text { advertising/GDP }\end{array}$ & 0.97 & $(0.39)$ & 0.000 & $(0.004)$ & 0.93 & $(0.05)$ \\
\hline HP cycle component & 0.41 & $(0.23)$ & - & - & - & - \\
\hline $\begin{array}{l}\text { Bandpass cycle } \\
\text { component }\end{array}$ & 0.36 & $(0.16)$ & - & - & - & - \\
\hline TV ads & 0.40 & $(0.71)$ & 0.014 & $(0.002)$ & 0.71 & $(0.03)$ \\
\hline Radio ads & 0.37 & $(0.55)$ & 0.008 & $(0.002)$ & 0.81 & $(0.04)$ \\
\hline Newspaper ads & 1.19 & $(0.51)$ & - & - & - & - \\
\hline Direct mail & -0.42 & $(0.49)$ & 0.011 & $(0.008)$ & 0.96 & $(0.04)$ \\
\hline Other advertising & 1.74 & $(0.54)$ & -0.011 & $(0.001)$ & 0.77 & $(0.08)$ \\
\hline
\end{tabular}

Note: The right-hand variable in the first row is in first differences. Regressions include constants, not shown.

Table 1: Cyclical Behavior of the Advertising/GDP Ratio

The filter absorbs any trend in $R_{t}$, so I do not include an explicit trend. For the filters, I use Hodrick-Prescott with smoothing parameter 6.25 and a bandpass filter that passes cycle periods of 2 through 8 years.

The data run from 1950 through 2010. In addition to total advertising, I also estimate equations for the major components: TV, radio, newspapers, direct mail, and other. Table 1 shows the results. In all cases but one, the estimated cyclical response- the coefficient on the employment rate - is positive, generally statistically unambiguously positive. The advertising/GDP ratio is plainly procyclical - it rises when employment rises. The relationship is much stronger for the random-walk and AR specifications of the low-frequency component - the HP and bandpass filters plainly absorb a good deal of the variation in the advertising/GDP ratio that would otherwise be associated with employment.

I reiterate that the finding that advertising is procyclical is not central to the point of the 
paper. Rather, the key finding is that advertising is not strongly countercyclical, as it would be if the profit margin were countercyclical. The findings in Table 1 are not dispositive on the unimportance of fluctuations in the profit margin, however, because there is a possibility that a strongly procyclical effect from the product-market friction is masking a countercyclical effect from the margin. To deal with this issue, I turn to a study of the cyclical movement of the labor share.

\section{The Labor Share}

The Bureau of Labor Statistics publishes a quarterly index of the labor share of non-financial corporations at bls.gov/lpc, series PRS88003173, starting in 1947. The limitation to corporations is desirable because there is no reliable basis for dividing proprietary income into labor and capital components. Figure 2 shows the data with bars shaded in proportion to the employment rate.

The labor share rises briefly but sharply at the beginning of a contraction, apparently because of labor hoarding. Similarly, it falls at the beginning of expansions, possibly because more intense work effort is the initial response to an increase in demand. To account for these transitory dynamics, I use the following specification to describe the cyclical movements of the labor share:

$$
\log \lambda_{t}=\omega_{\lambda}+\beta_{\lambda} L_{t}+\phi\left[L_{t}-\frac{1}{N}\left(L_{t-1}+\cdots+L_{t-N}\right)\right]+\mu_{\lambda, t}
$$

Here the coefficient $\beta_{\lambda}$ on the employment rate $L_{t}$ captures the cyclical behavior apart from the labor-hoarding aspect. $\phi$ is the coefficient of the term for labor-hoarding dynamics, $\omega_{\lambda}$ is a constant, and $\mu_{\lambda, t}$ is a slow-moving component of the labor share arising from other sources. I use the same four specifications for $\mu_{\lambda, t}$ as for the advertising/GDP ratio, $R$.

Table 2 shows the results of estimating the four specifications of the equation for the labor share. The transitory part of the specification uses $N=4$ lagged quarters of the employment rate. The top row uses the random-walk specification and the second row the $\mathrm{AR}(1)$ specification of the slow-moving component. Both find that the labor share is procyclical, with a semi-elasticity of 0.70 . That estimate is reasonably precise, with a standard error of 0.18 . The estimate confirms the presence of a transitory component in the

opposite direction. The immediate response of the share to an increase in employment - the difference between the first and second coefficient - is actually positive. 


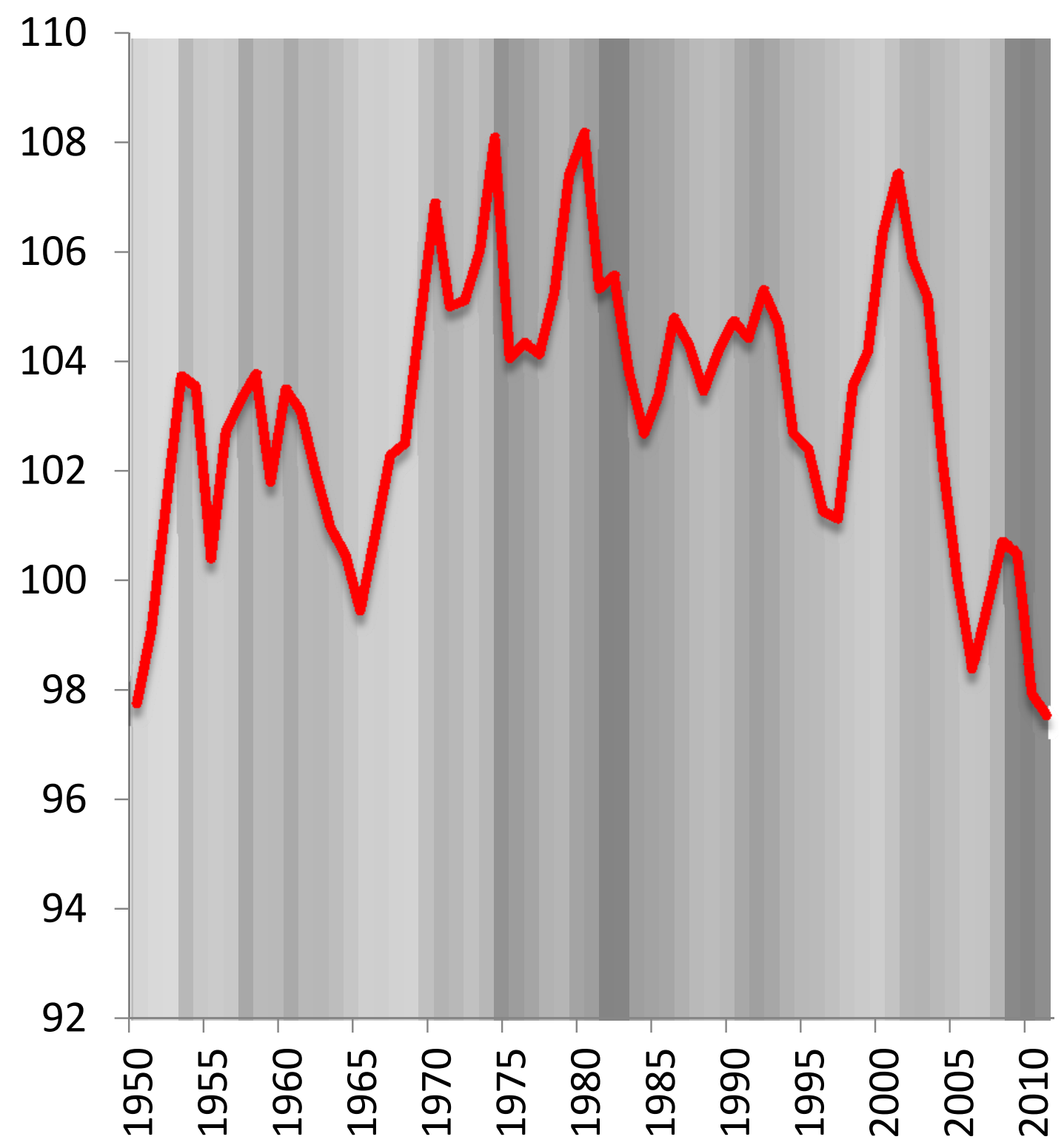

Figure 2: Index of the Labor Share of Non-Financial Corporate Income, with Shading in Proportion to the Employment Rate 


\begin{tabular}{lcccccc}
\hline \hline & \multicolumn{6}{c}{ Coefficients and standard errors } \\
\cline { 2 - 7 } \multicolumn{1}{c}{ Left-hand variable } & \multicolumn{5}{c}{$\begin{array}{c}\text { Departure of } \\
\text { employment rate } \\
\text { from recent past }\end{array}$} & Autoregressive term \\
\cline { 2 - 7 } $\begin{array}{l}\text { Change in log labor rate } \\
\text { share }\end{array}$ & 0.70 & $(0.18)$ & -1.24 & $(0.17)$ & - & - \\
$\begin{array}{l}\text { Log labor share } \\
\text { HP cycle component }\end{array}$ & 0.70 & $(0.18)$ & -1.23 & $(0.17)$ & 0.957 & $(0.019)$ \\
$\begin{array}{l}\text { Bandpass cycle } \\
\text { component }\end{array}$ & 0.27 & $(0.06)$ & -1.39 & $(0.14)$ & - & - \\
\hline \hline
\end{tabular}

Note: The two right-hand variables in the first row are in first differences.

Regressions include constants, not shown

Table 2: Cyclical Behavior of the Labor Share

The third and fourth lines in Table 2 use filtering methods on the share to account for its slower movements. They find semi-elasticities about half as large. The reported standard error is probably an overstatement of the reliability, as it does not account for the preliminary filtering.

I conclude that both the advertising/GDP ratio and the labor share are procyclical. This finding points strongly in the direction of an influence of the product-market friction that trumps any influence of the profit-margin wedge, given that the latter would stimulate a powerful countercyclical response of advertising.

\section{The Values of the Wedges and Their Effects on Em- ployment}

The empirical counterparts of the two wedges, including their low-frequency components, are

$$
\log M=\frac{\log R-\log \lambda}{\epsilon}
$$

and

$$
\log F=-\log \lambda-\frac{\log R-\log \lambda}{\epsilon} .
$$


Constructing these variables requires a value of the residual elasticity of demand $\epsilon$. As I noted earlier, though market power is an important topic in many branches of applied microeconomics and is the subject of a large literature, the results of empirical research are inconclusive with respect to any single value for $\epsilon$ that would typify the aggregate economy. Research has concentrated on packaged consumer goods and thus left most components of total production untouched. That said, most economists would probably place the typical value of the residual elasticity of demand in the range from 3 to 20, corresponding to profit margins of 33 down to 5 percent of price. I will present results for $\epsilon=6$, which corresponds to a markup ratio of $\epsilon /(\epsilon-1)=1.2$, along with a discussion of results for lower and higher amounts of market power.

Figure 3 and Figure 4 show the values of the two wedges, with slumps marked by dark bars, again shaded in proportion to the employment rate. The basic findings of the paper are plainly visible in these figures. Recall from equation (13) that the calculated value of the profit-margin wedge subtracts the log of the labor share from the log of the advertising/GDP ratio, which removes the common element of the two. That element is the log of the productmarket friction, $\log f$. What is left has almost no cyclical movement. On the other hand, $\log f$, calculated from equation (14) by using the calculated value of $\log m$ to remove the influence of that wedge from the labor share, is strongly countercyclical: Times of low employment coincide with high values of $\log f$.

\subsection{Role of the two wedges in employment volatility}

The main goal of this research is to quantify the contributions of $\log m$ and $\log f$ to the movements of the employment rate. A three-way breakdown is

$$
L_{t}=\theta \log m_{t}+\delta \log f_{t}+x_{t}
$$

where $x_{t}$ captures all the other influences on employment. The coefficients $\theta$ and $\delta$ are presumptively negative, because both wedges discourage employment. This equation is not a regression with $x_{t}$ playing the role of the disturbance, because $x_{t}$ is surely correlated with $\log m_{t}$ and $\log f_{t}$. But with outside information about the coefficients $\theta$ and $\delta$, it is possible to decompose the movements of $L_{t}$ into those attributable to each of the three components

on the right-hand side. The econometric issue of identification does not arise here, because no coefficients are estimated. 


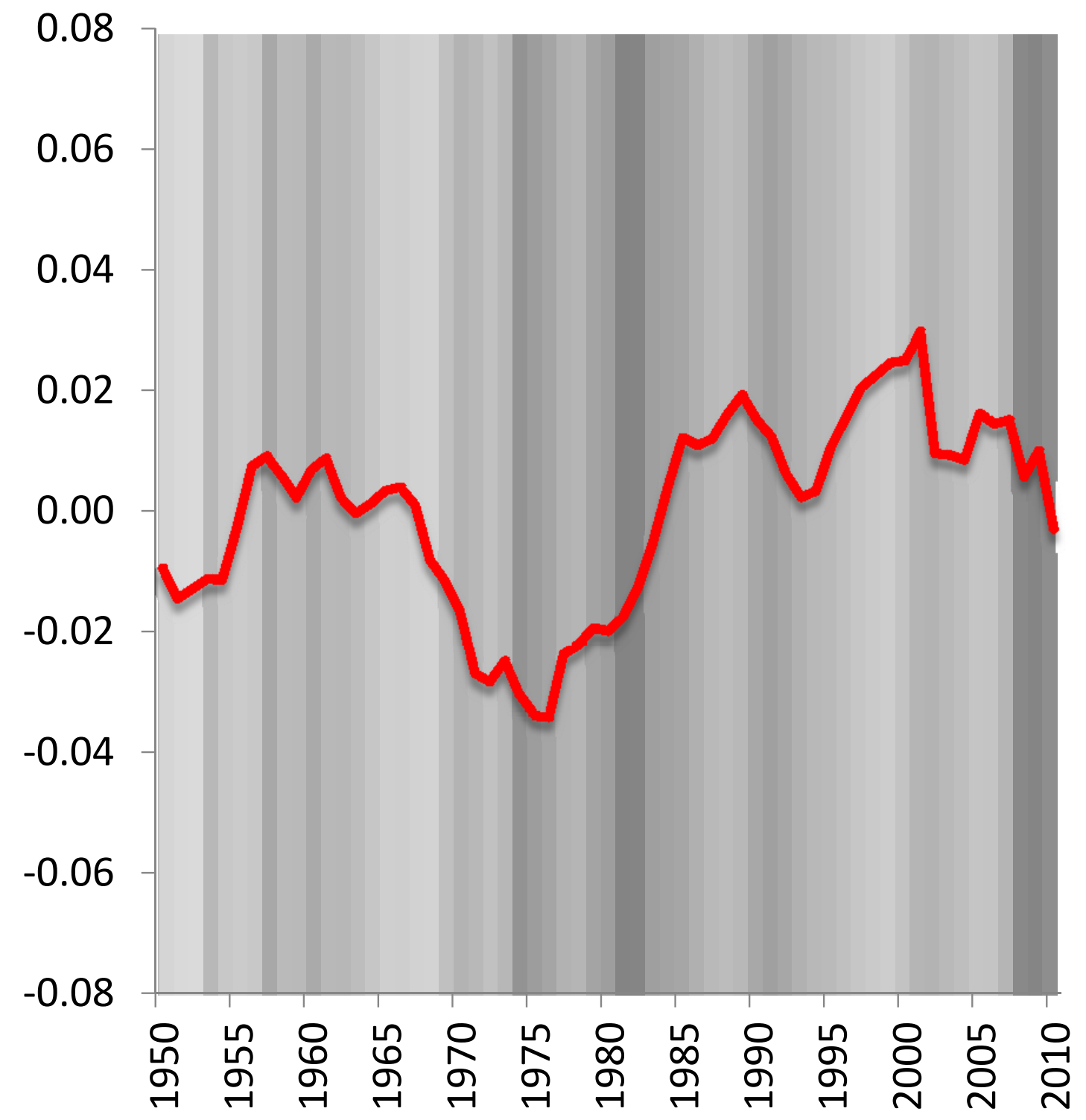

Figure 3: Calculated Time Series for the Profit-Margin Wedge, Including Low-Frequency Component 


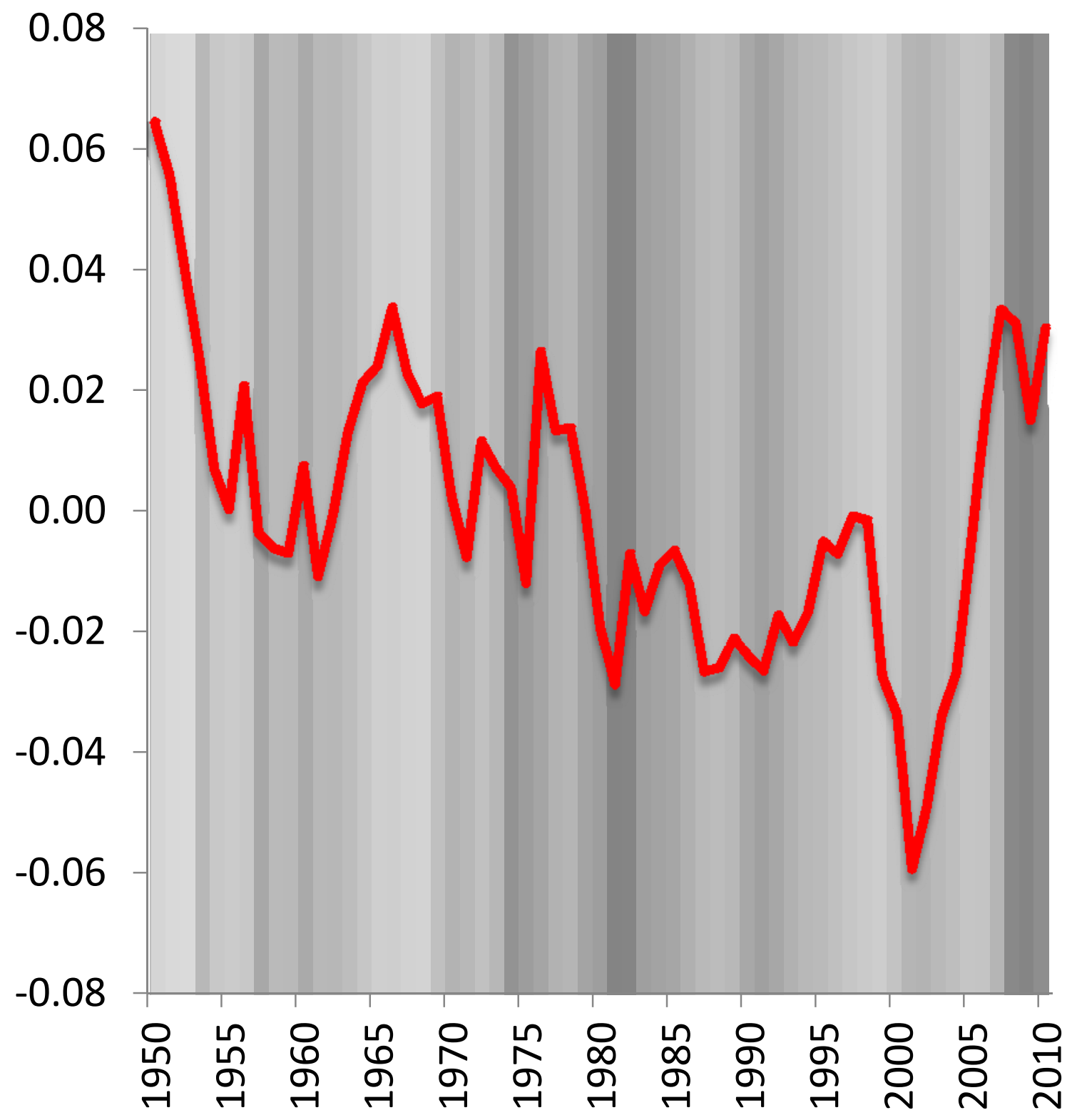

Figure 4: Calculated Time Series for the Product-Market Friction Wedge, Including LowFrequency Component 
Current macroeconomic theory characterizes the effects of aggregate driving forces in terms of wedges, notably $m$, which plays a key role in the New Keynesian model's transmission mechanisms to account for cyclical movements in employment and aggregate activity, as explained, for example, in Rotemberg and Woodford (1999). Wedges are intermediate variables, not exogenous driving forces.

The first helpful insight from macro theory is that the two coefficients $\theta$ and $\delta$ should have essentially the same value, say $\theta$. Theory suggests that all wedges combine to generate a single master wedge separating the marginal product of labor from the marginal value of time. The producer's contribution to the wedge is the ratio of the price paid by the consumer to the producer's cost. From equation (4), the ratio is

$$
m f \frac{\epsilon}{\epsilon-1} .
$$

The two variables $m$ and $f$ enter with equal elasticities of one.

Second, Hall (2009) suggests that the employment rate responds to the master wedge with a semi-elasticity of somewhat more than 1 in absolute value. I take $\theta=-1$ as the main case, but examine the consequences of lower and higher values.

The next step is to measure the contributions of $\theta \log m_{t}, \theta \log f_{t}$, and $x_{t}$ to the movements of the employment rate. The two series $\theta \log m_{t}$ and $\theta \log f_{t}$ contain slower-moving components, attributable to forces such as drift in the elasticity $\alpha$ of demand with respect to advertising and drift in the elasticity $\gamma$ of output with respect to labor. These components are prominent in Figure 3 and Figure 4. The paper is about cyclical movements. To focus on these, I use a combination of two tools. The first, as in the earlier sections on the cyclical movements of $R$ and $\lambda$, is to apply a filter to the data that attenuates the lower frequencies. The filter involves quasi-differences, such as

$$
\hat{m}_{t}=\log m_{t}-\rho \log m_{t-1} .
$$

For $\rho=1$, the filter that is most aggressive in isolating higher frequencies, the gain is zero at the lowest frequency. After filtering, the relation among the variables is

$$
\hat{L}_{t}=\theta \hat{m}_{t}+\theta \hat{f}_{t}+\hat{x}_{t}
$$

The second tool defines the cycle in terms of the movements of the employment rate, an idea that runs through the entire paper and receives its sharp definition here. Rather 
than looking at variances of the components, which treat all movements equally, I look at covariances with the employment rate. Covariances filter out movements not related to the cycle, given my definition that equates the cycle to movements in employment. An added benefit of this approach is that covariances are additive. The decomposition is

$$
\mathrm{V}\left(\hat{L}_{t}\right)=\theta \operatorname{Cov}\left(\hat{m}_{t}, \hat{L}_{t}\right)+\theta \operatorname{Cov}\left(\hat{f}_{t}, \hat{L}_{t}\right)+\operatorname{Cov}\left(\hat{x}_{t}, \hat{L}_{t}\right)
$$

Finally, I divide by the variance of the employment rate to get

$$
1=\theta \frac{\operatorname{Cov}\left(\hat{m}_{t}, \hat{L}_{t}\right)}{\mathrm{V}\left(\hat{u}_{t}\right)}+\theta \frac{\operatorname{Cov}\left(\hat{f}_{t}, \hat{L}_{t}\right)}{\mathrm{V}\left(\hat{L}_{t}\right)}+\frac{\operatorname{Cov}\left(\hat{x}_{t}, \hat{L}_{t}\right)}{\mathrm{V}\left(\hat{u}_{t}\right)} .
$$

Note that this can be written more compactly as

$$
1=\theta \beta_{m}+\theta \beta_{f}+\beta_{x}
$$

where the $\beta$ s are the coefficients of the corresponding variables regressed on $\hat{L}_{t}$. Earlier in the paper I mentioned that the regression of the log of the advertising/GDP ratio divided by the labor share on employment was highly informative about the cyclical role of the profit-margin wedge, $m$. The regression coefficient $\beta_{m}$ is exactly the coefficient from that regression. Similarly, $\beta_{f}$ is the regression of the product-market friction on the employment rate. The quantity $\theta \beta_{m}$ is the contribution of the profit-margin wedge, $\theta \beta_{f}$ is the contribution of the product-market friction wedge, and the remainder, $1-\theta \beta_{m}-\theta \beta_{f}$ is contribution of the residual. Because $\theta$ is negative and the two coefficients are presumptively negative, the contributions are presumptively positive (I say presumptively because it turns out that $\beta_{m}$ is actually, paradoxically, slightly but not significantly positive).

Earlier I estimated the coefficients of the filtered values of the advertising/GDP ratio $R_{t}$ and the labor share $\lambda_{t}$ on similarly filtered employment. These are $\beta_{R}$ and $\beta_{\lambda}$. Because regression is a linear operation and the coefficients $\beta_{m}$ and $\beta_{f}$ are linear functions of those coefficients - see equation (13) and equation (14) - the desired coefficients can be calculated directly from the earlier values:

$$
\beta_{m}=\frac{\beta_{R}-\beta_{\lambda}}{\epsilon}
$$

and

$$
\beta_{f}=-\frac{\beta_{R}+(\epsilon-1) \beta_{\lambda}}{\epsilon},
$$

These are, for the first-difference specification $(\rho=1)$ and $\theta=1$,

$$
\beta_{m}=\frac{0.97-0.70}{6}=0.04
$$


and

$$
\beta_{f}=-\frac{0.97+5 \times 0.70}{6}=-0.75
$$

The profit-margin wedge $m$ is slightly procyclical, contrary to expectation, while the productmarket friction wedge $f$ is robustly countercyclical, as expected.

Calculation of the standard errors of these estimates requires the covariance of the estimates of $\beta_{R}$ and $\beta_{\lambda}$. Because the first uses annual data and the second quarterly data, a bit of an econometric issue arises in calculating the covariance, as described in the appendix. The resulting standard errors are 0.06 and 0.18 . Thus the role of the profit-margin wedge $m$ is tightly circumscribed around zero and the role of the product-market friction is unambiguously substantially countercyclical.

The calculations above depend on the parameter $\theta$, the effect of wedges in general on the employment rate. Figure 5 shows how the calculation of the contributions depends on that parameter, using values of $\hat{m}_{t}$ and $\hat{f}_{t}$ calculated with $\epsilon=6$ and $\rho=1$. The horizontal axis is the absolute value of the effect of the wedge on employment, $\theta$. At $\theta=-1$, the profitmargin wedge $m$ accounts for -4 percent of the cyclical movements of the employment rate, the product-market wedge for 75 percent, and the other forces for the remaining 29 percent. For higher values of $|\theta|$, the product-market wedge accounts for an implausibly high fraction of the cyclical movements.

Table 3 reports the sensitivity of the results to two other determinants, the residual elasticity of demand, $\epsilon$, and the quasi-differencing coefficient, $\rho$. The base case described above is enclosed in a box. Removing the quasi-difference filtering completely, shown in the first row, results in an estimate of the procyclicality of the advertising/GDP ratio, $\beta_{R}$, of about half its value in the base case, but still positive. However, its confidence interval is wide and includes countercyclical values. I use the term procyclical loosely here because in the absence of any quasi-differencing, low frequencies have as big a role in the estimate as do cyclical frequencies. The labor share is cyclically neutral with zero quasi-differencing. The rest of the results in the first row of the table show that, without concentrating on cyclical frequencies, the procedure assigns small procyclical roles to the profit-margin wedge and small countercyclical roles to the product-market friction wedge. Most of the movements of the employment rate are assigned to the residual when the large low-frequency movements are included in the measured wedges.

The bottom row of Table 3 shows that the basic message of the paper - the strong coun- 


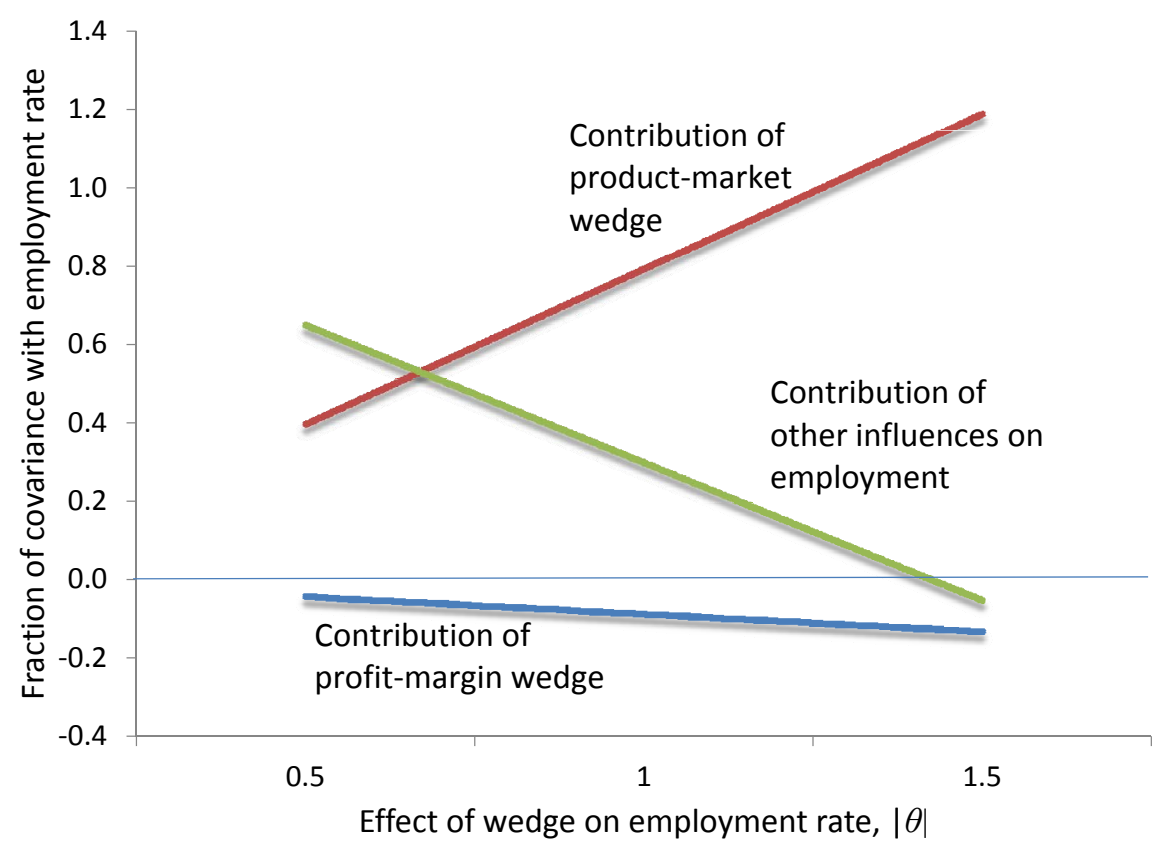

Figure 5: Contributions of Wedges to Employment Movements as Functions of the Parameter $\theta$

\begin{tabular}{|c|c|c|c|c|c|c|c|c|}
\hline \multirow{4}{*}{$\begin{array}{l}\rho, \text { annual } \\
\text { quasi- } \\
\text { difference } \\
\text { coefficient }\end{array}$} & \multirow{3}{*}{\multicolumn{2}{|c|}{ Estimated coefficients }} & \multicolumn{6}{|c|}{ Implied contributions of wedges to cyclical movements in the employment rate } \\
\hline & & & \multicolumn{6}{|c|}{$\varepsilon$, residual elasticity of demand } \\
\hline & & & \multicolumn{2}{|c|}{3} & \multicolumn{2}{|c|}{6} & \multicolumn{2}{|c|}{12} \\
\hline & $\beta_{R}$ & $\beta_{\lambda}$ & $\beta_{m}$ & $\beta_{f}$ & $\beta_{m}$ & $\beta_{f}$ & $\beta_{m}$ & $\beta_{f}$ \\
\hline 0 & $\begin{array}{c}0.46 \\
(0.73)\end{array}$ & $\begin{array}{c}0.06 \\
(0.10)\end{array}$ & $\begin{array}{c}0.13 \\
(0.25)\end{array}$ & $\begin{array}{c}-0.20 \\
(0.25)\end{array}$ & $\begin{array}{c}0.07 \\
(0.12)\end{array}$ & $\begin{array}{c}-0.13 \\
(0.15)\end{array}$ & $\begin{array}{c}0.03 \\
(0.06)\end{array}$ & $\begin{array}{l}-0.10 \\
(0.11)\end{array}$ \\
\hline 0.5 & $\begin{array}{c}0.74 \\
(0.57)\end{array}$ & $\begin{array}{c}0.45 \\
(0.14)\end{array}$ & $\begin{array}{c}0.09 \\
(0.20)\end{array}$ & $\begin{array}{l}-0.55 \\
(0.21)\end{array}$ & $\begin{array}{c}0.05 \\
(0.10)\end{array}$ & $\begin{array}{l}-0.50 \\
(0.15)\end{array}$ & $\begin{array}{c}0.02 \\
(0.05)\end{array}$ & $\begin{array}{l}-0.48 \\
(0.14)\end{array}$ \\
\hline 1 & $\begin{array}{c}0.97 \\
(0.37)\end{array}$ & $\begin{array}{c}0.70 \\
(0.18)\end{array}$ & $\begin{array}{c}0.09 \\
(0.13)\end{array}$ & $\begin{array}{c}-0.79 \\
(0.18)\end{array}$ & $\begin{array}{c}0.04 \\
(0.07)\end{array}$ & $\begin{array}{l}-0.75 \\
(0.17)\end{array}$ & $\begin{array}{c}0.02 \\
(0.03)\end{array}$ & $\begin{array}{l}-0.73 \\
(0.17)\end{array}$ \\
\hline
\end{tabular}

Note: the figure in the first colmn is the annual coefficient; the quarterly coefficient is that figure raised to the power $1 / 4$.

Table 3: Implications of Alternative Quasi-Differencing Coefficients and Residual Elasticities of Demand 
tercyclical role of the product-market wedge and the weak (and counterintuitive) role of the profit-margin wedge-holds for the wide range of values of the residual elasticity $\epsilon$.

In no case does the profit-margin wedge make any substantial contribution. With $\epsilon=6$, $\theta=1$, and $\rho=1$, the point estimate of the contribution is $-\beta_{m}=-0.04$ with a standard error of 0.07 . With confidence probability $1-p=0.75$, the results show that the contribution is zero or below. The confidence probabilities are 0.92 that $-\beta_{m} \leq 0.05$ and 0.98 that $-\beta_{m} \leq 0.1$. The evidence against any meaningful role for the profit-margin wedge is quite strong. Results for other values of the residual elasticity $\epsilon$ are equally strong. Without filtering in favor of cyclical frequencies $(\rho=0)$, the point estimate is the same (slightly negative) but the standard error is 0.13 , so the confidence probabilities are not as strong evidence against small positive value of $-\beta_{m}$.

On the other hand, the evidence in favor of positive values of the contribution $-\beta_{f}$ of the product-market wedge is strong in all cases. The point estimate with $\epsilon=6, \theta=1$, and $\rho=1$ is 0.79 with a standard error of 0.18 . The confidence probability that $-\beta_{f} \geq 0.4$ is 0.98 and that $-\beta_{f} \geq 0.6$ is 0.85 . As I noted earlier, this evidence depends on the restriction to cyclical frequencies.

\subsection{Potential overstatement of the procyclicality of the labor share}

The procyclical behavior of the labor share, as demonstrated in this paper and in a good deal of earlier work, has an important role in the conclusions of the paper. The two key equations mapping the observed cyclical behavior of advertising and the labor share into the underlying relations described by $\beta_{m}$ and $\beta_{f}$ can be written

$$
\beta_{m}=\frac{\beta_{R}-\beta_{\lambda}}{\epsilon}
$$

and

$$
\beta_{f}=-\beta_{m}-\beta_{\lambda}
$$

In the first equation, a substantially procyclical labor share (positive value of $\beta_{\lambda}$ ) results in a modest amount of cyclical variation in $m$, as reflected in a small value of $\beta_{m}$. In the second equation, because $\beta_{m}$ is small, the inferred value of the cyclical coefficient for the product-market friction wedge $f, \beta_{f}$, is close to the negative of the the coefficient measuring the procyclicality of the labor share, $\beta_{\lambda}$. The bottom line is a small role for the profit-margin wedge $m$ and a big countercyclical role for the product-market friction wedge $f$. 
Nekarda and Ramey (2010) and Nekarda and Ramey (2011) challenge the finding of a procyclical labor share. They conclude that the labor share, properly measured, is constant over the cycle. These authors, along with most of their predecessors, frame the question as the cyclical behavior of the markup ratio, so that it might appear that they estimate the cyclical movement of the profit margin wedge, $\beta_{m}$, rather than the cyclical movements captured by $\beta_{\lambda}$, in the notation of this paper. However, the earlier literature does not consider the cyclical role of the product friction $f$ introduced in this paper. Hence it is appropriate to consider their results as bearing on the labor share rather than the profit margin. Equation (12) in Nekarda and Ramey (2010) describes the relation between the labor share and the markup ratio. The variable considered in their work and in much of the earlier work is the reciprocal of the labor share, adjusted for overtime wages and for the elasticity of substitution. The latter adjustment has an effect only if the technology is not Cobb-Douglas. Their equation (13) is close to the one in this paper, except that the cycle indicator is not based on the employment rate.

If Nekarda and Ramey are correct that $\beta_{\lambda}=0$, the equations above become

$$
\beta_{m}=\frac{\beta_{R}}{\epsilon}
$$

and

$$
\beta_{f}=-\beta_{m}
$$

With $\beta_{R}=0.97$ as in the base case and $\epsilon=6$, the values are $\beta_{m}=0.16$ and $\beta_{f}=-0.16$, both with standard errors of 0.06 . The basic conclusions of the paper are qualitatively the same - the implied role for the profit-margin wedge is paradoxically procyclical rather than countercyclical, as wedges are generally thought to be in general and this one is taken to be in the New Keynesian model. The implied role for the product-market friction wedge $f$ is countercyclical, as it should be, but quite a bit smaller than in the base case.

\subsection{Conclusion about the role of profit-margin wedge and product- market frictions}

The findings point in the direction that $\beta_{m}$ is close to zero. Sticky prices are not an important factor in pricing. The suggestion that the data do not support the sticky-price hypothesis is not new. But the companion finding is new - that the data strongly support the hypothesis that firms encounter some kind of friction during slumps that makes them behave as if they were paying a higher tax on their output. 


\section{Advertising as Investment}

One reason that advertising is procyclical is that advertising is an investment that has a lasting benefit, extending beyond the period of the expenditure itself. Other types of investment-inventories and plant-equipment in particular-are quite procyclical, in the sense used in this paper, that the ratio of expenditure to revenue declines in a recession. In this section, I investigate whether the investment character of advertising is concealing a countercyclical movement of advertising spending driven by countercyclical margins.

The empirical literature on the effects of advertising has reached a reasonably strong consensus that most of the effect of advertising on sales occurs within a year-see Bagwell (2007), pages 1726 to 1728, for cites, and Corrado, Hulten and Sichel (2009) for a recent quantification and additional cites. The latter paper places the annual depreciation rate of advertising capital at 60 percent.

Nerlove and Arrow (1962) developed the theory of investment in depreciable advertising along the same lines as Jorgenson's (1963) famous model of investment in plant and equipment. The stock of advertising, $A_{t}$, evolves according to

$$
A_{t}=a_{t}+(1-\delta) A_{t-1}
$$

Here $a_{t}$ is purchases of new advertising and $\delta$ is the rate of depreciation.

The price of a unit of advertising — now thought of as the services of a unit of a stock of advertising over one year-is

$$
\kappa_{t}=\frac{r+\delta}{1+r} p_{t}
$$

Here $r$ is the annual real interest rate, $\delta$ is the annual rate of depreciation, and $p$ is the price of investment in advertising, which I take to be the price of goods and services in general. Notice that this formula is $\kappa_{t}=p_{t}$ if there is complete depreciation within a year: $\delta=1$.

The ratio of advertising expenditure to revenue is $\frac{\kappa_{t} A_{t}}{p_{t} Q_{t}}$. To form this ratio from the data, I calculate the advertising stock $A_{t}$ from the recursion, equation (39), using data on $a_{t}$ formed as the Coen data on advertising expenditure deflated by the price index for private GDP, starting in 1929. I calculate $\kappa$ using $\delta=0.6$ and $r=0.05$.

Table 4 compares the results from treating advertising as investment with those shown earlier in the paper, in the base case $(\epsilon=6$ and $\rho=1)$. The value of the cyclicality coefficient for the advertising/GDP ratio is considerably lower (about 0.2 instead of nearly 1), confirming that some of the procyclicality of the ratio arises from investment factors. 


\begin{tabular}{lcc|cc}
\hline \hline & $\beta_{R}$ & $\beta_{\lambda}$ & $\beta_{m}$ & $\beta_{f}$ \\
\cline { 2 - 5 } Base case & 0.971 & 0.703 & 0.045 & -0.747 \\
& $(0.370)$ & $(0.181)$ & $(0.065)$ & $(0.169)$ \\
Capital & 0.212 & 0.703 & -0.082 & -0.621 \\
& $(0.286)$ & $(0.181)$ & $(0.066)$ & $(0.168)$ \\
\hline \hline
\end{tabular}

Table 4: Comparison of Results for the Base Case and an Alternative with Advertising Treated as Capital

But the ratio remains procyclical, not countercyclical as it would be if the profit-margin wedge were an important factor in its movements. The cyclicality coefficient $\beta_{\lambda}$ remains the same, of course. The contributions of the two wedges are not changed much. The one for the profit-margin wedge, $\beta_{m}$, takes on the right negative sign, but the coefficient is small and sufficiently accurately estimated to rule out large negative values. The one for the product-market friction wedge, $\beta_{f}$, is a little smaller than in the base case, but remains robustly large. The basic finding of the paper - that the profit-margin wedge is unimportant and the product-market friction wedge is quite important - easily survives the switch to the investment approach.

\section{Other Influences}

To this point, the paper has compared two forces that affect the advertising/sales ratio $R$ and the labor share $\lambda$. These are the profit-margin wedge $m$ and the product-market friction wedge $f$. The evidence favors a small role for the margin wedge and a large role for the friction. A rise in the friction during slumps explains both the decline in $R$ during slumps and the decline in $\lambda$. A natural question is whether other influences could have the same effect. In this section I argue that the set of other influences is quite limited.

To consider the effects of other influences, I extend the model to include the following:

- A Hicks-neutral productivity index, $h$

- A labor wedge or measurement error, $f_{L}$

- A capital wedge or measurement error, $f_{K}$

- An advertising wedge or measurement error, $f_{A}$ 
For clarity, I refer to the product-market wedge $f$ as $f_{Q}$ in this section. For the three new $f$ wedges, I assume that the firm pays an amount per unit that is the wedge times the reported price; for example, the firm pays an actual wage bill of $f_{L} W$ when the reported wage bill is $W$. Marginal cost $c$ is now a function of $h, f_{L}$ and $f_{K}$. But in the derivation of the advertising spending/revenue ratio $R$, leading up to equation (7), neither $c$ nor its determinants make their way into $R$. The new wedge $f_{A}$ does affect the ratio in the extended model:

$$
R=\frac{\kappa A}{p Q}=\frac{\alpha}{f_{A} f_{Q} m} \frac{(m-1) \epsilon+1}{\epsilon}
$$

From the derivation of equation $(10)$, it is apparent that only the labor wedge $f_{L}$ enters the formula for the labor share $\lambda$ :

$$
\lambda=\frac{W}{p Q}=\frac{1}{f_{L} f_{Q} m} \gamma \frac{\epsilon-1}{\epsilon}
$$

The appendix contains complete derivations for $R$ and $\lambda$.

These conclusions follow:

- The Hicks-neutral productivity index $h$ and the capital wedge or measurement error $f_{K}$ affect neither the advertising/sales ratio $R$ nor the labor share $\lambda$.

- The new wedge $f_{A}$ affects $R$ with an elasticity of -1 and the new wedge $f_{L}$ affects $\lambda$ with an elasticity of -1 ; the margin wedge $m$ remains the only wedge that has a high elasticity.

- The advertising wedge or measurement error, $f_{A}$, lowers $R$ in the same way that $f_{Q}$ does.

- The labor wedge or measurement error, $f_{L}$, lowers $\lambda$ in the same way that $f_{Q}$ does.

- Equal values of $f_{A}$ and $f_{L}$ have the same effect as $f_{Q}$ of the same value.

The relations between the estimated coefficients $\beta_{R}$ and $\beta_{\lambda}$ and the underlying coefficients describing the cyclical responses of the profit-margin wedge $\left(\beta_{m}\right)$, the product-market friction wedge $\left(\beta_{f}\right)$, the advertising wedge $\left(\beta_{A}\right)$, and the labor wedge $\left(\beta_{L}\right)$, become:

$$
\beta_{R}=\text { Semi-elasticity of } R \text { with respect to } L=(\epsilon-1) \beta_{m}-\beta_{f}-\beta_{A}
$$

$$
\beta_{\lambda}=\text { Semi-elasticity of } \lambda \text { with respect to } L=-\beta_{m}-\beta_{f}-\beta_{L}
$$


With four unknown coefficients and two equations, none of the unknowns is identified. Conditional on values of the new coefficients $\beta_{A}$ and $\beta_{L}$, the values of the coefficients for the wedges studied earlier are:

$$
\beta_{m}=\frac{\beta_{R}-\beta_{\lambda}}{\epsilon}+\frac{\beta_{A}-\beta_{L}}{\epsilon}
$$

and

$$
\beta_{f}=-\frac{\beta_{R}+(\epsilon-1) \beta_{\lambda}}{\epsilon}-\frac{\beta_{A}+(\epsilon-1) \beta_{L}}{\epsilon} .
$$

I let $\hat{\beta}_{m}$ and $\hat{\beta}_{f}$ be the estimates discussed earlier in the paper, computed from the first term in each of the equations above. The bias in these estimates in the presence of the new wedges is revealed by rewriting the equations as

$$
\hat{\beta}_{m}=\beta_{m}+\frac{\beta_{L}-\beta_{A}}{\epsilon}
$$

and

$$
\hat{\beta}_{f}=\beta_{f}+\frac{\beta_{A}+(\epsilon-1) \beta_{L}}{\epsilon} .
$$

In both equations, the bias from the advertising wedge is attenuated by division by the residual elasticity of demand $\epsilon$. The same is true of the labor wedge in the first equation. The key conclusion of the paper is that the contribution of the profit-margin wedge, $\beta_{m}$, is small and slightly procyclical (positive), rather than large and countercyclical (negative) as in the New Keynesian model. Only a very large countercyclical coefficient for the advertising wedge (big negative $\beta_{A}$ ) or a very procyclical coefficient for the labor wedge (big positive $\beta_{L}$ ) would have much effect in concealing a large role for the profit-margin wedge through the bias term in the first equation.

A countercyclical advertising wedge would imply that the properly measure ratio of advertising spending to sales was less procyclical or even countercyclical, which would raise the implied value of the contribution of the profit-margin wedge $\beta_{m}$. Nothing comes to mind that would suggest such a phenomenon. If the cyclical response $\beta_{A}$ is bounded from below by -1.0 , removing the bias would add at most 0.2 to the contribution of the profit-margin wedge to fluctuations in employment.

A procyclical labor wedge seems even more unlikely. My earlier discussion of Nekarda and Ramey's position that the labor share is cyclically neutral applies to the possibility. But a procyclical wedge makes the labor share appear to more countercyclical than it really is. Nekarda and Ramey propose the opposite, that the labor share appears to be more procyclical than it really is. Thus they sponsor the view that $\beta_{L}=-0.7$, so as to make the 
true labor share cyclically neutral when the measured one has a semi-elasticity of 0.7 , as found earlier in this paper. In my earlier discussion of their position, I noted that it implied a value of the contribution of the profit-margin wedge that was even more paradoxically positive. I am not aware of any consideration that would point in the opposite direction, toward a procyclical labor wedge that would results in a substantially negative value of $\beta_{m}$, fulfilling the New Keynesian hypothesis that countercyclical shifts in profits account for cyclical variations in employment.

With respect to the primary conclusion of the paper that $\beta_{m}$ is small, I conclude that the extended model is not successful in identifying a plausible source of variation that overcomes the high positive elasticity of advertising with respect to the profit margin. Imputing a substantial countercyclical error in measuring the price of advertising is implausible. A countercyclical error in measuring the labor share goes in the wrong direction.

The second major conclusion of the paper is that the contribution of the product-market friction wedge, $\beta_{f}$, is large and negative. This conclusion is more sensitive to consideration of additional wedges, notably the labor wedge. Earlier I noted that accepting the proposition from Nekarda and Ramey that the correct value of $\beta_{\lambda}$ is zero, because of a countercyclical measurement error with $\beta_{L}=-0.7$, implies that the contribution of the product-market friction is only 0.16 , far below the value of 0.75 in the base case in this paper.

\section{Concluding Remarks}

Macroeconomists have become fond of invoking rising profit margins to explain the many puzzles of slumps. I think it will be important for these model-builders to bring the behavior of advertising into the variables under consideration. It's hard to overcome the implication that advertising is really, really sensitive to profit margins. The obvious conclusion from the failure of advertising to explode in recessions is that profit margins remain about the same when the economy contracts.

If so, we need to redouble efforts to track down the sources of poor economic performance in long-lasting slumps. 


\section{References}

Bagwell, Kyle, "The Economic Analysis of Advertising," in M. Armstrong and R. Porter, eds., Handbook of Industrial Organization, Volume 3, Elsevier, 2007, chapter 28, pp. $1701-1844$.

Bils, Mark, "The Cyclical Behavior of Marginal Cost and Price," American Economic Review, December 1987, 77 (5), 838-855.

_ _ "Pricing in a Customer Market," Quarterly Journal of Economics, November 1989, 104 (4), 699-718.

_ and James Kahn, "What Inventory Behavior Tells Us about Business Cycles," American Economic Review, June 2000, 90 (3), 458-481.

Blank, David M., "Cyclical Behavior of National Advertising," The Journal of Business, 1962, 35 (1), pp. 14-27.

Borden, Neil Hopper, The Economic Effects of Advertising, Chicago: Irwin, 1942.

Bresnahan, Timothy F., "Empirical Studies of Industries with Market Power," in Richard Schmalensee and Robert D. Willig, eds., Handbook of Industrial Organization, Volume II, Amsterdam: North-Holland, 1989, chapter 17, pp. 1011-1057.

Chevalier, Judith A. and David S. Scharfstein, "Capital-Market Imperfections and Countercyclical Markups: Theory and Evidence," The American Economic Review, 1996, 86 (4), pp. 703-725.

Corrado, Carol, Charles Hulten, and Daniel Sichel, "Intangible Capital and U.S. Economic Growth," Review of Income and Wealth, 2009, 55 (3), 661-685.

Dorfman, Robert and Peter O. Steiner, "Optimal Advertising and Optimal Quality," The American Economic Review, 1954, 44 (5), pp. 826-836.

Edmond, Chris and Laura Veldkamp, "Income Dispersion and Counter-Cyclical Markups," Journal of Monetary Economics, 2009, 56, 791-804. 
Hall, Robert E., "Reconciling Cyclical Movements in the Marginal Value of Time and the Marginal Product of Labor," Journal of Political Economy, April 2009, 117 (2), 281323.

Hausman, Jerry, Gregory Leonard, and J. Douglas Zona, "Competitive Analysis with Differenciated Products," Annals of Economics and Statistics / Annales d'conomie et de Statistique, 1994, (34), pp. 159-180.

Jorgenson, Dale W., "Capital Theory and Investment Behavior," The American Economic Review, 1963, 53 (2), pp. 247-259.

Kaldor, Nicholas, "The Economic Aspects of Advertising," The Review of Economic Studies, 1950, 18 (1), pp. 1-27.

Loecker, Jan De and Frederic Warzynski, "Markups and Firm-Level Export Status," American Economic Review, May 2012, 102 (6), 2437-71.

Nekarda, Christopher J. and Valerie A. Ramey, "The Cyclical Behavior of the Price-Cost Markup," June 2010. University of California, San Diego.

_ _ and _ _ "Industry Evidence on the Effects of Government Spending," American Economic Journal: Macroeconomics, January 2011, 3 (1), 36-59.

Nerlove, Marc and Kenneth J. Arrow, "Optimal Advertising Policy under Dynamic Conditions," Economica, 1962, 29 (114), pp. 129-142.

Rotemberg, Julio J. and Michael Woodford, "The Cyclical Behavior of Prices and Costs," in John Taylor and Michael Woodford, eds., Handbook of Macroeconomics, Volume 1B, Amsterdam: North-Holland, 1999, chapter 16, pp. 1051-1135.

Simon, Julian L., Issues in the Economics of Advertising, Urbana: University of Illinois Press, 1970.

Yang, Charles Yneu, "Variations in the Cyclical Behavior of Advertising," Journal of Marketing, 1964, 28 (2), pp. 25-30. 
Bibtex: QUNPUBLISHED $\{$ Hall:Ads, author $=\{$ Hall, Robert E. $\}$, title $=\{$ The Cyclical Response of Advertising Refutes Countercyclical Profit Margins in Favor of Product-Market Frictions $\}$, note $=\{$ Hoover Institution, Stanford University $\}$, month $=\{$ November $\}$, year $=\{2012\}\}$ 


\section{A Full Derivation for Advertising}

Optimal price:

$$
p^{*}=\frac{\epsilon}{\epsilon-1} f_{Q} c
$$

Actual price:

$$
p=m p^{*}
$$

First-order condition for advertising:

$$
\frac{\alpha}{A} Q\left(\frac{p}{f_{Q}}-c\right)=f_{A} \kappa
$$

From above,

$$
c=\frac{\epsilon-1}{\epsilon} \frac{p}{m f_{Q}}
$$

The first-order condition becomes

$$
\frac{\alpha}{A} \frac{p Q}{f_{Q}} \frac{(m-1) \epsilon+1}{\epsilon m}=f_{A} \kappa
$$

and, finally,

$$
R=\frac{\kappa A}{p Q}=\frac{\alpha}{f_{A} f_{Q} m} \frac{(m-1) \epsilon+1}{\epsilon}
$$

\section{B Full Derivation for Labor Share}

With cost minimization and Cobb-Douglas technology, labor cost is a fixed share $\gamma$ of total cost:

$$
\frac{f_{L} W}{c Q}=\gamma
$$

Substitute for $c$ :

$$
f_{L} f_{A} m \frac{\epsilon}{\epsilon-1} \frac{W}{p Q}=\gamma
$$

so

$$
\lambda=\frac{W}{p Q}=\frac{1}{f_{L} f_{Q} m} \gamma \frac{\epsilon-1}{\epsilon}
$$

\section{Data Sources}

Table 5 gives further information about sources of advertising data. 


\begin{tabular}{|c|c|c|c|}
\hline $\begin{array}{l}\text { Type of } \\
\text { advertising }\end{array}$ & Source & Years & Reference \\
\hline Newspapers & $\begin{array}{l}\text { Newspaper Association } \\
\text { of America }\end{array}$ & 1950-2011 & $\begin{array}{l}\text { http://www.naa.org/Trends- } \\
\text { and-Numbers/Advertising- } \\
\text { Expenditures/Annual-All- } \\
\underline{\text { Categories.aspx }}\end{array}$ \\
\hline All types & Douglas Galbi & $1900-2007$ & $\begin{array}{l}\text { http://purplemotes.net/2008/ } \\
\text { 09/14/us-advertising- } \\
\text { expenditure-data/ }\end{array}$ \\
\hline \multirow[t]{2}{*}{ All types } & & 1994-2004 & $\begin{array}{l}\text { http://www.census.gov/prod/ } \\
\underline{\text { www/abs/bus-services.html }}\end{array}$ \\
\hline & Census Bureau & 2005-2010 & $\begin{array}{l}\text { http://www.census.gov/servi } \\
\text { ces/index.html }\end{array}$ \\
\hline
\end{tabular}

Table 5: Sources for Advertising Data

\section{Covariance of Estimates of $\beta_{R}$ and $\beta_{\lambda}$}

The covariance matrix of the vectors of estimates, say $\hat{\theta}_{R}$ and $\hat{\theta}_{\lambda}$, is

$$
\mathbb{E}_{X_{R}, X_{\lambda}}\left[\left(\hat{\theta}_{R}-\theta_{R}\right)\left(\hat{\theta}_{\lambda}-\theta_{\lambda}\right)^{\prime}\right]=\left(X_{R}^{\prime} X_{R}\right)^{-1} X_{R}^{\prime} \mathbb{E}\left(\eta_{R} \eta_{\lambda}^{\prime}\right) X_{\lambda}\left(X_{\lambda}^{\prime} X_{\lambda}\right)^{-1}
$$

I assume that the covariance matrix of the disturbances $\eta_{R}$ and $\eta_{\lambda}$ is $I \otimes\left(\sigma_{R, \lambda} \iota\right)$, where $I$ is a $T_{R} \times T_{R}$ identity matrix, $\otimes$ is the Kronecker product, $\sigma_{R, \lambda}$ is the covariance of $\eta_{R, t}$ and any $\eta_{\lambda, t^{\prime}}$ with $t^{\prime}$ in the same year as $t$, and $\iota$ is a $1 \times 4$ vector of ones. In words, both disturbances are serially uncorrelated and have only a contemporaneous cross-correlation, which is equal across the 4 quarters of the year. Under this assumption, the covariance matrix of the estimates is

$$
\sigma_{R, \lambda}\left(X_{R}^{\prime} X_{R}\right)^{-1} X_{R}^{\prime} \bar{X}_{\lambda}\left(X_{\lambda}^{\prime} X_{\lambda}\right)^{-1}
$$

where $\bar{X}_{\lambda}$ is a matrix of annual sums of the variables in $X_{\lambda}$. The desired covariance of $\beta_{R}$ and $\beta_{\lambda}$ is the appropriate element of this matrix. 